\title{
Placemaking through Dasein: Painting Tropical Space
}

\author{
Angela Meyer \\ Stephen Naylor \\ Richard Lansdown
}

\author{
James Cook University
}

\begin{abstract}
This paper looks at the role of art in understanding place as a construct of the imagination, reactions to the real and lived experience. The making of a place by the activities and actions within place constitute over time notions of what things are, what they mean and how meaning is constructed from symbolism and kinaesthesia. Placemaking establishes the meaning of a spatial context by symbolic gestures, objects and experiences. Dasein internalises inherent meaning from being in space where; "Dasein is thoroughly temporal," and, "self and world are a unity" (Guignon, 2006, p. 134). These things together formulate the temporal frontier of culture as a transient space of activity and evolution. The tropics as a framework were explored in my research through artists painting the wet tropics of North Queensland.
\end{abstract}

\section{Introduction}

$\mathrm{T}$ o understand place through its constructed symbolic meaning reflected in the art that emerges from the geographical site within the contemporary context of North Queensland I considered the viewpoint of tropical space against the view temperate space. Naturalists and explorers including Joseph Banks, Alexander von Humboldt, Charles Darwin, Richard Spruce, Alfred Russel Wallace, Henry Walter Bates, and William Jackson Hooker differentiated the temperate zone from the torrid zone. This European idea of the tropics was described by David Arnold in The Tropics and the Travelling Gaze (2006). Understanding local tropical space engages the painter in a discourse on human geography and the tropical sensibility. The personal experience of painting is not only an artistic premise; it also recognizes a spiritual connection to community and place. Tropical representations in art, literature and science reveal the complexity and contradictory interpretations of tropical nature, extraordinary in its variety of ecosystems and contrasts.

Aside from the distinctions of hierarchical views of space, the theory of how people exist in relation to space is considered here in the theory of Dasein in relation to placemaking.

Placemaking is an active involvement of doing things in a particular space that turns it into a place of habitation with meaning about its cultural context which produces place: the activity of doing is the kinaesthetic learning and internalising of experience to understand and gather knowledge. Dasein defined by Heidegger is a state of already being-in-the-world, where beings arrive in the world with inherent meaning, context and existing spatial relationships to the activity and objects around them. 
The lens through which I look at these terms is the tropics as a space and place, its historical perceptions in western thought, its lived occupation and its representation in paintings. In this immersive state of a person's involvement with the world: "The world is not something external but is constituitive of Dasein. We are born into a world where culture and history helps make us who we are" (Guignon, 2006, p. 134). The imagery from the tropical world captured in paintings from memory and painting traditions expresses a current view produced in and from the tropics as a response to the history of tropicality as a European concept.

Guignon continues that Dasein explains how we are in the world through our relationship to the world via "average everydayness" where the worldliness is about "being in relation" to the world (Guignon, 2006, p. 134). These aspects of a person's relationship to the world around them constitute, "understanding and state of mind" (Guignon, 2006, p. 134). Guignon further explains Heidegger's Dasein as an infrastructure of "care" based on living in the world as "existentiality, facticity and fallenness" where these things together combine to form a "three dimensionality of lived experience of time as the "ecstatic" unity of time (Guignon, 2006, p. 135).

The idea of seeing the tropics as separate and autonomous from the temperate view is understood through the notion of placemaking, where the study of place "is both simple (and that is part of its appeal) and complicated" (Cresswell, 2004, p. 1). This is because it is both geographical and it also sits within our everyday interaction with our surroundings. Human geography charts taking ownership of geographical space by using it in a particular way, "A common strategy is to make the space say something about you," through possessions, objects and the arrangement of the symbols and motifs in order that, "space is turned into place," (Cresswell, 2004, p. 2); which could simply be a room in a house (Bachelard, 1994). Creswell's examples of the way space is turned into place includes things like decorating personal space and arranging furniture; projecting cultural identity through tourist brochures, postage stamps and architecture; or designing public venues such as parks that can be sites of pleasure, political protest or shelter for the homeless. The use of space determines its manifestation as place.

Terry Smith (Smith, 2010) describes placemaking as a contemporary current within the discourse of post-modernism, where eclecticism and globalisation rethink the aesthetics of geographical space. Political geographer John Agnew describes place through: location, locale and sense of place to create a 'meaningful location' (Cresswell, 2004, p. 7), where; "Indeed, in the end it is the concrete effects of places that matter more than remaining at the abstract level of conceptualising place" (Agnew, 2011, p. 5).

The whereabouts of place can also come from memory, nature and culture as Lucy Lippard states, "At the same time, senses of place, a serial sensitivity to place, are invaluable social and cultural tools, providing much-needed connections to what we call nature and, sometimes, to cultures not our own" (Lippard, 1997, p. 33). Complacency toward place must also be held in view: "The comforts of a familiar and beloved place are real, she suggests, but easy sentimentality can blind us to what's happening there" (Hine, 1997). This highlights the need to understand place through its connectivity's, power structures, political perspectives and characteristics; and in this survey through painting. Agnew considered the concept of a region as a platform for being within space. He writes: 
The conflict between these two dominant meanings, space versus place, is longstanding. Indeed, the vicissitudes of the argument in geography over such definitional issues as regions, spatial analysis, and human-environment relations involve competing conceptions of space and place as much as distinctive views about the nature of science or the relative virtues of quantitative methods. Outside of geography, little critical attention has been given to either definition, yet, of course, implicitly one has been adopted. By definition, everything happens somewhere. Typically, the definition adopted has been the view of place as a location where things "just happen" rather than the more holistic view of places as the geographical context for the mediation of physical, social and economic processes (Agnew, 2011, pp. 3-4).

\section{Tropical space as a painted vision}

To understand tropical aesthetics Gavin Wilson's Escape Artists exhibition (1998) attempts to portray North Queensland in his view of what tropical space looks like. For his Escape Artists exhibition he focussed on a group of painters who had escaped to the tropics to paint work in the modernist tradition. Wilson considered the visual processes of modernist painting to entail personalising an experience and constructing a symbolic form to represent the object of the experience: "As modernist images, they possess a type of synergy that simultaneously contains the object and the subject, the world outside the individual and the artists themselves" (Wilson, 1998, p. 12). Through painted images of the tropics a constructed space emerges. Wilson weighted his argument for the represented tropics on the goals of escapism because, "To escape is to free oneself" (Wilson, 1998, p. 11). In the act of immersion the escape artists responded through pictures to produce symbolic motifs of place, like John Firth-Smith' works Trap, At Home, Billabong, John Olsen's painting Nolan at Broome and Alan Oldfield's Lizard King. However, the question that arises out of the curator's vision that challenges the meaning of tropical space, whilst trying to describe it. Wilson's view of tropical north Queensland is an experience of Other, especially as a focus on geography outside the immediate locale.

Terry Smith considers the agency of place defined by a reflection on contemporary cultural activity: "Placemaking, world picturing and connectivity are the most common concerns of artists these days because they are the substance of contemporary being" (Smith, 2010, p. 380). The idea of being in Heidegger is a fundamental process of linking the experience of the sensory world to the signifiers of physical life. Heidegger's model of Dasein understands the primacy of experience, which I have accessed to portray the tropics as quantifiers from lived experience, including tangibles like geography, regional location, local culture, recent and ancient history. The present and the past tense are reflected in Heidegger's Origin of the Work of Art (1950), in which his notion of the role of art is to consider truthfulness of people's existence. Heidegger writes:

The origin of the work of art - that is, the origin of both the creators and the preservers, which is to say of a people's historical existence - is art. This is so because art in its essence is an origin: a distinctive way in which truth comes into being, that is, becomes historical (cited in Krell, 1977, p. 202).

Heidegger reasoned that artists' access truth through "bestowing, grounding and beginning," that uses art to document history: "Art is history in the essential sense that it grounds history," (cited in Krell, 1977, p. 202). Art presents a practical way to understand place as a particular kind of space as imaged in the works. In the context of art history and tropical 
geography, the studio-as-laboratory (Sullivan, 2009) is a crucial research site to locate arts practice, where painting is employed to synthesise the ideas of an imaginary, real and participatory investigation of a real or imagined tropics.

Information collected from the case study artists I interviewed demonstrated the exploration of the tropics through painting as a theory of description where "definite descriptions purport to pick out a single object" (Griffin, 2003, p. 203). The object of space was reclassified into smaller sub-spaces, in order to determine its meaning through case study artists who painted the wet tropics of North Queensland. The ability to then view the descriptions as sets of marks, patterns, colours, forms, characters and lines provides an analysis of the perception of the tropics. Claire Souter explains; "sound, colour and smell are sensations that I am aware of. They all go in and they come out. I'm just painting and those things are there" (personal communication, Souter, 2010). For Heidegger, truth in art is either an appeal to the past as preliminary reflective knowledge, or a forward projection and framed by the ability to see it. He writes:

Almost from the time when specialized thinking about art and the artist began, this thought was called aesthetic. Aesthetics takes the work of art as an object, the object of aesthesis, of sensuous apprehension in the wide sense. Today we call this apprehension lived experience (cited in Krell, 1977, p. 204).

Aesthetics derived from the inner world of thought, as well as the observed physical world brings together fact and fantasy. Heidegger continues,

The way in which man experiences art is supposed to give information about its essence. Lived experience is the source that is the standard not only for art appreciation and enjoyment but also for its artistic creation (cited in Krell, 1977, p. 204).

The tropics in reality has been a site at once desirable, degenerate, excessive, controlled, sublime and strange (Driver and Martins, 2005; Stepan, 2001; Segalen, 2002; Lansdown, 2006). Stepan argues that even empirical models of the tropics are shaped by "codes of seeing and representational conventions," where "we easily forget that they are just representations and take them for literal transcriptions of reality... all representations and pictures of the world, even the most technical and scientific are partial and selective" (Stepan, 2001, pp. 1415). Inside the paradoxical struggle to articulate the tropics in its hybrid nature, difference emerges as imperative. To dwell on the idea of the tropics as a particular kind of space, celebrates the difference, and portrays the material world of the tropics through a complex view. The lived perspective acquired through the descriptive language of the case study artists aimed to expand the question of picturing space:

All these red brown leaves, not dead leaves, they are new leaves, they are red, not black like they are burnt, but rather sunburnt, with colour, they are so delicate and pretty, you don't think of the rainforest as being delicate and pretty (personal communication, James Baines, 2010).

In contrast to an exemplar of invention of tropicality is in the oeuvre of Henri Rousseau used his imaginative projection to reach into the tropics; he accessed the exotic experience Segalen called "elsewhere" through the idea of escape. In pursuit of mystery and distance, he used escape as a way to discover an experience of difference (Segalen, 2002, p. xvi). This is 
perceptible in Rousseau's kaleidoscope of hieroglyphic patterns and enchanted monsters, both fearful and benign. "According to Apollinaire, Rousseau was sometimes so overcome when painting," jungle imagery with men being eaten by jaguars, "that he would become terrified and, all atremble, would be obliged to open the window" (Alley,1978, pp. 70-71).

The experience of immersion given to us by another French painter Gauguin, is his journey and lived experience of Tahiti, as a peopled world of extravagance and subjugation (Eisenman, 1997) did not trivialise difference as the Other or fashionable exotica. He refused to see it as "... a sequence of fashionable crazes in the second half of the nineteenth century" that embraced designs from the Middle east, South Asia and the Far East (Netton, 2012, p. 121). But Gauguin's position in Tahiti is complex; Solomon-Godeau questions the primitivist mythology of sexual outlaw to declare that violent domination is unacceptable. SolomonGodeau continues that this aids to 'linchpin' his mythology, because "what is at stake in the erotics of primitivism is the impulse to domesticate, as well as possess" (Solomon-Godeau, 1989, p. 326). Gauguin's flawed vision is not only exotic and sensual, but also represents Gauguin's "affinity for tropical life," as, "he was deeply aware of his atavism" (Dora, 1953). The French vision is furthered in Matisse's formal use of decoration as hieroglyphic expression where, "ornament was seen as a cultural fossil, an artefact that retained clues to the origins of art-making" (Connelly, 1995, p. 55).

Australian artists who deal with painting the tropics to test the theory of difference can be seen by comparing Arthur Streeton, who painted Barron Gorge with Heidelberg eyes in muted tones, and Ray Crooke who painted Fiji and the wet tropics of North Queensland with the bright colours of the French vision. The blueprint of the French fascination accentuates the modernist interpretations in Crooke, Olley, Friend and Williams. The case study artists I sampled lent a vision to access North Queensland through its flashes of iridescent blue in butterflies and flowers enhanced by atmospheric light effects. Painting in the tropics charts being in equatorial space through its detail, rhythms and visual spectacle. While Australia's earlier painting aesthetics were primarily influenced by British painting styles and quieter colour, I sourced the French painters' reactions to tropical space, because they filled their canvases with the bright hues of the tropics.

The important distillation of the meaning of the tropics presented by the case study artists gave a context for my arts practice. This was overlayed with narrative stories/dramas/themes. The idea of shadows of the underworld contrasted with the concept of tropical paradise beneath the veneer of the fluorescent cartoon of bright colour projected as the antithesis of paradise. The point of the study was to find how contemporary painting practice communicates a tropical aesthetic or sensibility in local space as current discourse.

\section{Discussion of case studies results}

The interview responses include the artists' descriptions of external reality, as well as the feelings and meanings of their internal world. Explanations of the sensory tropics included responses from: Claudine Marzik who uses the surface texture of the natural environment, which she translates into surface texture on her canvases. Ian Smith said he carries his experience of the tropics within him. James Baines has an ambivalent relationship with the tropics, speaking about the spiky plants and the spoliation due to human impact. Baines' tropics are both dystopic and magically iridescent with flashes of bright colour; however he struggles with the colour green, as it symbolises the overabundant rainfall and wild 
vegetation, revealing the tropics as claustrophobic. Claire Souter states that spirituality is personal and nature is in a perpetual state of decline.

Amanda Feher said her relationship to her surroundings is instinctive and the uniqueness of the tropics fuels her work. Margaret Olley whose youthful impression of colour was shaped by her childhood in Tully was also inspired by Gauguin's prints while at high school in Brisbane. Laurine Field used the plant species at the Flecker Botanic Gardens for a series of paintings based on the relationship between humans and plants where the garden is an overtly constructed tropics. Ray Crooke saw the vegetation, people and colour of the tropics as a pictured world ready to transcribe onto canvas.

While the French lens contributed to a vision of the tropics as a place of paradox, immersion, primitivism, exoticism, and the decorative; it is the intensely abstract world of the Other that can only produce fear of the demonic and fascination of the quixotic. "Primitive idols were disliked by Europeans and were frequent targets for destruction because they seemed to embody the irrational superstitions and savagery of uncivilised peoples" (Connelly, 1995, p. 81). However the Other understood as diversity and alterity gives a crucial insight to the importance of ethnicity and difference (Spivak, 1990). In the way Segalen intended to unpack its meaning, exoticism was a truthful understanding of difference. It was separate from colonial reductionism, which he explained through aesthetics and ontology. Ray Crooke explained his observation of indigenous artists:

I got familiar with the people... They had a lot of these various stones. They made all of the stones into patterns and that meant something. That stone is a waterfall, and that's a waterhole, and that is something else... and instead of using stones they are putting on dots... it could go on forever, moving these stones around, or just dots of paint (personal communication, Ray Crooke, 2010).

Placemaking has been interpreted here as a dynamic and complex activity within the site of tropical nature that inspires artists to respond, in a sensory capacity inside the continuum of Dasein as a state of being in space that becomes place. "The Chrisitan view that "we are in the world, but not of the world' is transformed. We are both in and of the world. 'Worldliness' is an ontological property of Dasein; it is our context of involvements" (Guignon, 2006, p. 134). It can also be understood inasmuch as, "Place is not just a thing in the world but a way of undersatanding the world" (Cresswell, 2004, p. 11). Wilson's escape artists aimed to define something of the tropical experience and the case study presented here revealed local insight.

\section{Works Cited}

Agnew, J. A. (2011). Space and place. In: Agnew, J. \& D. Livingstone (Eds.), Handbook of Geographical Knowledge. London: Sage.

Alley, R. (1978). Portrait of a primitive: The art of Henri Rousseau. Oxford: Phaidon.

Arnold, D. (2006). The tropics and the traveling gaze: India, landscape, and science, 18001856. Seattle, WA: University of Washington Press. 
Bachelard, G. (1994). The poetics of space. Boston, MA: Beacon Press.

Connelly, F. S. (1995). The sleep of reason: Primitivism in modern European art and aesthetics, 1725-1907. University Park, PA: The Pennsylvania State University Press.

Dora, H. (1953). The first Eves in Gauguin's Eden. Gazette des beaux-arts, 189-98.

Driver, F., \& Martins, L. 2005. Tropical visions in an age of Empire. Chicago, IL: The University of Chicago Press.

Eisenman, S.F. (1997). Gauguin's skirt. London: Thames and Hudson.

Griffin, N. (2003). The Cambridge companion to Bertrand Russell. Cambridge: Cambridge University Press.

Guignon, C.B. (2006). The Cambridge companion to Heidegger. Cambridge: Cambridge University Press.

Hine, T. (1997). All over the place. The New York Times on the web [Online]. Retrieved from: https://www.nytimes.com/books/97/08/17/reviews/970817.17hinelt.html [Accessed 2.12.2015].

Krell, D.F. (1977). Martin Heidegger basic writings. San Francisco, CA: Harper Collins.

Lansdown, R. (2006). Strangers in the south seas: The idea of the Pacific in western thought. Hawaii, HI: University of Hawai'i Press.

Lippard, L.R. (1997). The lure of the local: Senses of place in a multicentered society. New Press.

Netton, I. R. (2012). Orientalism revisited: Art, land and voyage. Oxon: Taylor \& Francis.

Segalen, V. (2002). Essay on exoticism: An aesthetics of diversity (post-contemporary interventions). London: Duke University Press.

Smith, T. (2010). The State of Art History: Contemporary Art. Art Bulletin, XCII, 380.

Solomon-Godeau, A. (1989). Going native: Paul Gauguin and the invention of primitivist modernism. Art in America, 118.

Spivak, G. C. (1990). The post-colonial critic: Interviews, strategies, dialogues. New York, NY: Routledge.

Stepan, N. L. (2001). Picturing tropical nature. New York, NY: Cornell University Press.

Sullivan, G. (2009). Art practice as research: Inquiry in the visual arts. New York, NY: Sage.

Wilson, G. (1998). Escape artists: Modernists in the tropics. Cairns: Cairns Regional Gallery. 